\title{
RANK/OPG ratio of expression in primary clear-cell renal cell carcinoma is associated with bone metastasis and prognosis in patients treated with anti-VEGFR-TKIs
}

B Beuselinck ${ }^{\star}, 1,2,3,15, J$ Jean-Baptiste ${ }^{1,2,15}$, G Couchy $^{1,2}, \mathrm{~S} \mathrm{Job}^{4}$, A De Reynies ${ }^{4}$, P Wolter ${ }^{3}$, C Théodore ${ }^{5}$, G Gravis $^{6}$, B Rousseau ${ }^{7}$, L Albiges ${ }^{8}$, S Joniau ${ }^{9}$, V Verkarre ${ }^{10}$, E Lerut ${ }^{11}$, J J Patard ${ }^{12}$, P Schöffski ${ }^{3}$, A Méjean ${ }^{13}$, R Elaidi $^{14}$, S Oudard $^{2,14}$ and J Zucman-Rossi ${ }^{1,2,14}$

${ }^{1}$ Inserm, UMR-1162, Génomique Fonctionnelle des Tumeurs Solides, IUH, rue Juliette Dodu 27, F-75010 Paris, France; ${ }^{2}$ Université Paris Descartes, Sorbonne Paris Cité, Faculté de Médecine, rue de l'Ecole de Médecine 15, F-75006 Paris, France; ${ }^{3}$ Department of General Medical Oncology and Laboratory for Experimental Oncology, University Hospitals Leuven, Leuven Cancer Institute, KU Leuven, Herestraat 49, B-3000 Leuven, Belgium; ${ }^{4}$ Programme Cartes d'Identité des Tumeurs, Ligue Nationale Contre le Cancer, rue Corvisart 14, F-75013 Paris, France; ${ }^{5}$ Department of Medical Oncology, Hôpital Foch, rue Worth 40, F-92150 Suresnes, France; ${ }^{6}$ Department of Medical Oncology, Institut Paoli-Calmettes, 232 Boulevard de Sainte-Marguerite, F-13273 Marseille, France; ${ }^{7}$ Department of Medical Oncology, Assistance Publique-Hôpitaux de Paris, Hôpital Henri Mondor, Avenue du Maréchal de Lattre de Tassigny 51, F-94000 Créteil, France; ${ }^{8}$ Department of Medical Oncology, Institut Gustave Roussy, rue Edouard Vaillant 114, F-94800 Villejuif, France; ${ }^{9}$ Department of Urology, University Hospitals Leuven, Leuven Cancer Institute, KU Leuven, Herestraat 49, B-3000 Leuven, Belgium; ${ }^{10}$ Department of Pathology, Assistance Publique-Hôpitaux de Paris, Hôpital Necker-Enfants Malades, rue de Sèvres 149, F-75015 Paris, France; ${ }^{11}$ Department of Pathology, University Hospitals Leuven, KU Leuven, Herestraat 49, B-3000 Leuven, Belgium; ${ }^{12}$ Department of Urology, Hôpital Bicêtre, rue du Général Leclerc 78, F-94270 Le Kremlin-Bicêtre, France; ${ }^{13}$ Department of Urology, Assistance Publique-Hôpitaux de Paris, Hôpital Européen Georges Pompidou, Rue Leblanc 20, F-75015 Paris, France and ${ }^{14}$ Department of Medical Oncology, Assistance Publique-Hôpitaux de Paris, Hôpital Européen Georges Pompidou, Rue Leblanc 20, F-75015 Paris, France

Background: Bone metastases (BMs) are associated with poor outcome in metastatic clear-cell renal carcinoma (m-ccRCC) treated with anti-vascular endothelial growth factor tyrosine kinase inhibitors (anti-VEGFR-TKIs). We aimed to investigate whether expression in the primary tumour of genes involved in the development of BM is associated with outcome in m-ccRCC patients treated with anti-VEGFR-TKIs.

Methods: Metastatic clear-cell renal cell carcinoma patients with available fresh-frozen tumour and treated with anti-VEGFR-TKIs. Quantitative real-time PCR (qRT-PCR) for receptor activator of NF-kB (RANK), RANK-ligand (RANKL), osteoprotegerin (OPG), the proto-oncogene SRC and DKK1 (Dickkopf WNT signalling pathway inhibitor-1). Time-to-event analysis by Kaplan-Meier estimates and Cox regression.

Results: We included 129 m-ccRCC patients treated between 2005 and 2013. An elevated RANK/OPG ratio was associated with shorter median time to metastasis (HR 0.50 (95\% Cl 0.29-0.87); $P=0.014)$, shorter time to BM (HR 0.54 (95\% Cl 0.31-0.97);

*Correspondence: Dr B Beuselinck; E-mail benoit.beuselinck@uzleuven.be

${ }^{15}$ These authors contributed equally to this work.

Revised 27 August 2015; accepted 2 September 2015; published online 13 October 2015

(c) 2015 Cancer Research UK. All rights reserved 0007-0920/15 
$P=0.037)$, shorter median overall survival (mOS) since initial diagnosis ( $\mathrm{HR} 2.27(95 \% \mathrm{Cl} 1.44-3.60) ; P=0.0001)$, shorter median progression-free survival (HR 0.44 (95\% Cl 0.28-0.71); $P=0.001$ ) and mOS (HR 0.31 (95\% Cl 0.19-0.52); $P<0.0001$ ) on first-line antiVEGFR-TKIs in the metastatic setting. Higher RANK expression was associated with shorter mOS on first-line anti-VEGFR-TKIs (HR $0.46(95 \% \mathrm{Cl} 0.29-0.73) ; P=0.001)$.

Conclusions: RANK/OPG ratio of expression in primary ccRCC is associated with BM and prognosis in patients treated with antiVEGFR-TKIs. Prospective validation is warranted.

About one-third of all metastatic clear-cell renal cell carcinoma (m-ccRCC) patients display bone metastases (BMs; Beuselinck et al, 2011). In m-ccRCC patients treated with anti-vascular endothelial growth factor tyrosine kinase inhibitors (anti-VEGFRTKIs), the presence of BM is a negative prognostic marker: in a series of $223 \mathrm{~m}$-ccRCCs treated first line with sunitinib, we observed a median progression-free survival (mPFS) of $8.2 v s 19.1$ months $(P<0.0001)$ and a median overall survival $(\mathrm{mOS})$ of 19.5 vs 38.5 months $(P<0.0001)$ in patients with and without bone involvement. RR on sunitinib was $35 \%$ and $55 \%$, respectively (Beuselinck et al, 2011). The impact of the presence of BM on RR and/or mOS was confirmed in subsequent publications (Patil et al, 2011; Motzer et al, 2013; McKay et al, 2014).

Recently, our team has described an expression profile-based classification of ccRCCs with four robust molecular subgroups (Beuselinck et al, 2015). These subtypes are associated with distinct $\mathrm{RR}, \mathrm{mPFS}$ and $\mathrm{mOS}$ when treated with sunitinib in first-line metastatic setting. ccrcc3 ('normal like') and ccrcc2 ('classical') tumours are associated with good, ccrccl tumours ('c-myc-up') with intermediate and ccrcc4 tumours ('c-myc-up and immuneup') with poor outcome in terms of RR, mPFS and mOS.

Several genes such as RANK, RANKL, OPG, SRC and DKK1 were previously identified associated with the development of BM. In bone, receptor activator of NF- $k B$ ligand (RANKL) binds to receptor activator of NF- $k \mathrm{~B}$ (RANK) stimulating osteoclast formation, activity and survival. Osteoprotegerin (OPG), produced by osteoblasts and stromal cells, is a soluble decoy receptor for RANKL and potent inhibitor of bone resorption. Through its binding to RANKL, OPG inhibits osteoclast differentiation by preventing RANKL-RANK interactions (Jung et al, 2004). SRC is an important determinant for bone tropism. DKK1, as a WNT protein antagonist, inhibits osteoblasts and stimulates osteoclasts (Clezardin and Teti, 2007).

These five genes can be expressed by ccRCC cells. RANK and RANKL are both present on the surface of tumour cells at a higher level than in normal kidney tissue (Clezardin and Teti, 2007; Mikami et al, 2009). RANK expression correlates with a more aggressive behaviour of the tumour. OPG expression is lower in ccRCC cells than in normal kidney tissue (Mikami et al, 2009). SRC is often overexpressed in renal cell carcinoma (RCC) and cancer cells can secrete DKK1.

The RANK/RANKL/OPG pathway is not only involved in bone destruction in patients with $\mathrm{BM}$ but also in cell migration, osteoclast-independent tumorigenesis and de novo metastasis. RANKL triggers the migration of tumour cells expressing RANK to the bone and to other organs. In a series of 96 ccRCCs, elevated RANKL and RANK expression with low OPG expression in the primary RCC tumour was significantly associated with shorter disease-free survival, shorter BM-free survival and shorter diseasespecific survival (Mikami et al, 2009). DKK1 acts as a tumour suppressor gene that induces apoptosis and inhibits proliferation in human RCC (Hirata et al, 2011).

Nevertheless, the impact of the expression levels of these genes on outcome in m-ccRCC patients treated with anti-VEGFR-TKIs is unknown. We aimed to investigate the relationship between tumour expression of RANK, RANKL, SRC, OPG and DKK1 with the occurrence of (bone) metastasis in ccRCC and with outcome in $\mathrm{m}$-ccRCC treated with anti-VEGFR-TKIs.

\section{MATERIALS AND METHODS}

In the tumour bank of the Hôpital Européen Georges Pompidou (Paris, France), and the University Hospitals Leuven (Belgium), we searched for m-ccRCC patients treated with sunitinib, sorafenib or pazopanib as first-line anti-VEGFR-TKIs with available archived frozen primary tumour. All patients underwent nephrectomy as first therapeutic intervention and the moment of nephrectomy was considered as the moment of initial diagnosis of the disease. Previous immunotherapy or chemotherapy was allowed, but previous exposure to other targeted therapies was an exclusion criterion. The study was approved by the Ethics Committee of the different institutions. Signed consent was obtained from all patients. In some cases, we used biological material from patients who had already died and for whom a general positive advice for the utilisation of remaining tissue was foreseen by the institutional board.

Using the High Capacity Transcription kit from Life Technologies (Thermo Fisher Scientific, Waltham, MA, USA), $500 \mathrm{ng}$ of total RNA was reverse transcribed in a final volume of $50 \mu \mathrm{l}$. Quantitative RT-PCR reactions were performed using the highthroughput BioMark qRT-PCR system (Fluidigm, South San Francisco, CA, USA). Preamplifications of $6 \mathrm{ng}$ cDNA were performed using PreAmp Master Mix (Thermo Fisher Scientific). A primer mix was prepared combining each primer used in the present study except the RNA actine-B (ACTB) probe. A measure of $1 \mu \mathrm{l}$ of TaqMan PreAmp Master Mix (Thermo Fisher Scientific) was mixed with $1 \mu \mathrm{l}$ of the pooled primer mix and $3 \mu \mathrm{l}$ of diluted cDNA $(2 \mathrm{ng} / \mu \mathrm{l})$, and incubated at $95^{\circ} \mathrm{C}$ for $2 \mathrm{~min}$ and 14 cycles of $95^{\circ} \mathrm{C}$ for $15 \mathrm{~s}$ and $60^{\circ} \mathrm{C}$ for $4 \mathrm{~min}$. Pre-amplified cDNAs were diluted 1:5 in DNAse/RNAse-free water before qRT-PCR. Gene expression mRNA was analysed by $\mathrm{qRT}-\mathrm{PCR}$ performed in Dynamic Array Integrated Fluidic Circuits on the Biomark HD system (Fluidigm, South San Francisco, CA, USA). We combined $3.5 \mu \mathrm{l}$ of Taqman Gene Expression Master Mix (Applied Biosystems, Foster City, CA, USA) and $0.35 \mu \mathrm{l} 20 \times$ GE Sample Loading Reagent (GE Healthcare Life Sciences, Little Chalfont, Buckinghamshire, UK) with $3.15 \mu$ l of diluted pre-amplified cDNA and transferred $5 \mu \mathrm{l}$ from this previous mix to the sample inlets of a 96.96 Dynamic Arrays. Quantitative RT-PCR was performed on the BioMark HD reader (Fluidigm, $50{ }^{\circ} \mathrm{C}$ for $2 \mathrm{~min}, 70^{\circ} \mathrm{C}$ for $30 \mathrm{~min}, 25^{\circ} \mathrm{C}$ for $10 \mathrm{~min}, 96.5^{\circ} \mathrm{C}$ for $10 \mathrm{~min}$, followed by 40 cycles of $96.5^{\circ} \mathrm{C}$ for $15 \mathrm{~s}$ and $60^{\circ} \mathrm{C}$ for $1 \mathrm{~min}$ ). Expression data (CT values) were acquired using the Fluidigm qRT-PCR Analysis software (4.1.3, Fluidigm). ACTB was used for the normalisation of expression data. Supplementary Table 1 provides the gene symbol, gene name and Applied Biosystems Assay ID number for the genes studied. All time-to-event analyses were carried out with $\Delta$-CT normalised expression data. The comparison between expression levels in normal and tumoral tissue and the correlation with the expression profile-based ccRCC classification were analysed with $2-\Delta \Delta \mathrm{CT}$ normalised expression data. 
The International Metastatic RCC Database Consortium (IMDC) prognostic score was retrospectively calculated for each patient (Heng et al, 2009). Patients underwent follow-up medical imagery (with ultrasonography and RX chest or computed tomography of the chest and abdomen) every 3-6 months between initial nephrectomy and the diagnosis of metastases and follow-up computed tomography (chest and abdomen) every 2-3 months during anti-VEGFR-TKI treatment. Bone scintigraphy, a modality with low sensitivity to detect osteolytic BMs, was made on clinical indication. Pathology slides were reviewed by expert genitourinary pathologists. All tumour samples were classified according to the molecular ccrcc1-4 classification (Beuselinck et al, 2015).

Endpoints of the study were time to metastasis (defined as the time between nephrectomy and development of metastases) and time to BM (defined as the time between nephrectomy and development of $\mathrm{BM}$ ), mOS since initial diagnosis of the primary tumour and outcome on first-line anti-VEGFR-TKIs as measured by RR, mPFS and mOS since start of anti-VEGFR-TKIs. In most cases, an objective response was defined according to Response Criteria in Solid Tumours (RECIST 1.0). Bone metastases were detected by computed tomography and bone scintigraphy. Patients who stopped therapy for toxicity before reaching the first evaluation were excluded. We studied the impact of the five individual genes on the end points. As OPG is the natural antagonist of RANKL, we also studied the impact of the RANK/OPG and RANKL/OPG ratio.

Expression levels were compared with unpaired $T$-test and ANOVA. Proportions were compared with Fisher exact test. The association between the different factors and time to events was studied by a Cox proportional hazards model. $P$-values were calculated with the log-rank Mantel-Cox test. Factors with a $P<0.2$ in univariate analysis were considered for multivariate analysis. A Bonferroni correction was used to exclude false-positive results due to multiple testing. Given the fact that in this study we correlated the expression level of five genes and two ratios of expression with six end points, we divided the threshold for significance of $<0.05$ by 42 . Thus, the new threshold for significance of the $P$-value was $<0.0012$. This Bonferroni correction was in particular important for the novel associations between expression levels and MPFS and mOS on treatment with anti-VEGFR-TKIs in the metastatic setting. Concerning the association between the expression levels of these genes and the development of (bone) metastases, as well as OS since initial diagnosis, we found that our data are a validation of the data of Mikami et al (2009). In a validation perspective, a Bonferroni correction is not strictly required. Statistical analysis was performed using Prism GraphPad (GraphPad Software, La Jolla, CA, USA) and Addinsoft XLStat (Addinsoft, Paris, France).

\section{RESULTS}

Included patients. We identified 129 patients with frozen nephrectomy specimens corresponding to the inclusion criteria (France: 74, Belgium: 55). Median follow-up of the patients was 144 months since initial diagnosis (range 3-225) and 75 months since the start of anti-VEGFR-TKIs (range 1-108). Table 1 shows the patient characteristics and Supplementary Figure 1, a flowchart with the inclusion in the different sub-studies. Concerning the time-to-metastasis analysis (Supplementary Figure 1A): in 56 patients, the nephrectomy was performed in a curative intent, but all these patients eventually developed metachronous metastases: these patients were included in the time-to-metastasis analysis. In 68 patients, the nephrectomy was performed in the presence of synchronous metastases and in the five remaining patients, the precise moment of development of metastasis was unknown. Concerning the time-to-BM analysis (Supplementary Figure 1B): in 12 patients, BMs were present at initial diagnosis; the remaining 117 patients were included in the time-to-BM analysis. Concerning the analysis of mOS since initial diagnosis, all patients were evaluable. Concerning the analysis of efficacy on anti-VEGFR-TKIs in the metastatic setting (Supplementary Figure 1C): all patients were evaluable for mOS after start of first-line anti-VEGFR-TKIs. In two patients, BMs were the only site of metastasis at start of anti-VEGFR-TKIs. As it was not possible to define RECIST response in these patients, they were excluded from the PFS and RR analysis.

Gene expression in normal and tumoral kidney tissue and correlation with the ccrcc classification and copy-number gains/losses. We observed higher RANK $(P=0.003)$, lower SRC $(P=0.002)$ and lower OPG expression $(P=0.003)$ in tumours compared with normal kidney $(n=9)$. DKK1 and RANKL expression were similar in tumours compared with normal tissue (Supplementary Figure 2). Gene expression was not correlated except for OPG and SRC $\left(r^{2}=0.138 ; P<0.0001\right.$; Supplementary Table 2). All the genes demonstrated a Gaussian distribution of their expression level and we further analysed the data using the median value of each gene as cutoff (Supplementary Figure 3). DKK1 $(P=0.01)$ and OPG expression $(P<0.0001)$ were higher and RANK expression $(P=0.03)$, RANK/OPG ratio $(P<0.0001)$ and RANKL/OPG ratio $(P=0.0008)$ lower in good prognosis ccrcc2/ccrcc3 tumours compared with intermediate prognosis ccrccl and poor prognosis ccrcc4 tumours. SRC expression was significantly higher in $\operatorname{ccrcc} 3$ tumours compared with the other subgroups $(P=0.002)$. Copy-number data were available for 84 patients. No association between mRNA expression and copynumber gains or losses was found at locus 18q22 (RANK), 8q24 (OPG), 13q14 (RANKL) and 20q12 (SRC). Copy-number data for 10q11 (DKK1) were not available.

Gene expression and time to metastasis. A total of 56 patients who underwent a nephrectomy with curative intent were included in this analysis. They all eventually developed metachronous metastases after a median time to metastasis of 16 months. On univariate analysis, lower DKK1 expression $(P=0.01)$ and an elevated RANK/OPG ratio $(P=0.03)$ were associated with shorter median time to metastasis (Table 2; Figure 1A). Higher T-stage at initial diagnosis (T3 or T4 vs T1 or T2) $(P=0.03)$ and higher Fuhrman grade (grade 4 vs grade $1+2+3 ; P=0.17$ ) were associated with shorter median time to metastasis with a $P<0.2$. Sarcomatoid dedifferentiation ( $\leqslant 25 \%$ vs $>25 \%$; $P=0.9)$, sex $(P=0.37)$, 8Q24 amplification $(P=0.26)$, the molecular ccrcc1-4 classification $(P=0.48)$ and age at diagnosis (median; $P=0.74$ ) were not. Two multivariate analyses were carried out, including T-stage (recoded as $\mathrm{T} 1+2$ vs $\mathrm{T} 3+4$ ), Fuhrman grade and DKK1 expression or the RANK/OPG ratio. DKK1 expression was not associated with time to metastasis. The RANK/OPG ratio was independently associated with time to metastasis (HR 0.50 (95\% CI 0.29-0.87); $P=0.014$ ). The results for the RANK/OPG ratio did not reach the level of significance calculated after Bonferroni correction for multiple testing $(P<0.0012)$. Nevertheless, these results are an external validation of the results of Mikami et al (2009).

Gene expression and time to BM. Only patients $(n=117)$ without $\mathrm{BM}$ at nephrectomy were included in this analysis. In 52 patients, BM appeared later during the course of the disease after a median time to BM of 26.5 months. A total of 65 patients remained $\mathrm{BM}$ free at the time of analysis. In the total group of patients without BM at nephrectomy, median time to BM was 77 months. An elevated RANK/OPG ratio was associated with a shorter median time to BM $(P=0.04$; Figure $1 \mathrm{~A}$; Table 2$)$. During the whole course of the disease, $86 \%$ of the patients with tumours with an elevated RANK/OPG ratio developed BM, compared with $49 \%$ 
Table 1. Included patients

\begin{tabular}{|c|c|c|c|c|}
\hline & Total & $\begin{array}{c}\text { RANK/OPG } \\
>\text { median }\end{array}$ & $\begin{array}{c}\text { RANK/OPG } \\
<\text { median }\end{array}$ & $P$-value \\
\hline \multicolumn{5}{|l|}{ Patient characteristics at initial diagnosis } \\
\hline Mean age (years) & 60 & 60 & 61 & NS \\
\hline Male & $71 \%(92 / 129)$ & $70 \%(45 / 64)$ & $72 \%(47 / 65)$ & NS \\
\hline $\begin{array}{l}\text { T-stage at diagnosis } \\
\text { T1 + T2 } \\
\text { T3 + T4 }\end{array}$ & $\begin{array}{l}31 \%(40 / 127) \\
69 \%(87 / 127)\end{array}$ & $\begin{array}{l}33 \%(21 / 63) \\
67 \%(42 / 63)\end{array}$ & $\begin{array}{l}30 \%(19 / 64) \\
70 \%(45 / 64)\end{array}$ & $\begin{array}{l}\text { NS } \\
\text { NS }\end{array}$ \\
\hline Metastasis at initial diagnosis & $52 \%(65 / 124)$ & $53 \%(31 / 59)$ & $52 \%(34 / 65)$ & NS \\
\hline $\begin{array}{l}\text { Fuhrman } \\
\text { Grades 1-3 } \\
\text { Grade } 4\end{array}$ & $\begin{array}{l}40 \%(52 / 129) \\
60 \%(77 / 129)\end{array}$ & $\begin{array}{l}30 \%(19 / 64) \\
70 \%(45 / 64)\end{array}$ & $\begin{array}{l}51 \%(33 / 65) \\
49 \%(32 / 65)\end{array}$ & 0.015 \\
\hline $\begin{array}{l}\text { Sarcomatoid dedifferentiation (Beuselinck et al, 2014) } \\
0 \% \\
1-24 \% \\
\geqslant 25 \%\end{array}$ & $\begin{array}{r}66 \%(82 / 125) \\
26 \%(32 / 125) \\
8 \%(10 / 125)\end{array}$ & $\begin{array}{l}60 \%(37 / 62) \\
27 \%(17 / 62) \\
13 \%(8 / 62)\end{array}$ & $\begin{array}{c}73 \%(46 / 63) \\
24 \%(15 / 63) \\
3 \%(2 / 65)\end{array}$ & $\begin{array}{l}0.11 \\
\text { NS } \\
0.035\end{array}$ \\
\hline $\begin{array}{l}\text { ccRCC classification } \\
\text { Ccrcc1 (c-myc-up) } \\
\text { Ccrcc2 (classical) } \\
\text { Ccrcc3 (normal like) } \\
\text { Ccrcc4 (c-myc-up and immune-up) }\end{array}$ & $\begin{array}{l}33 \%(38 / 116) \\
41 \%(47 / 116) \\
12 \%(14 / 116) \\
15 \%(17 / 116) \\
\end{array}$ & $\begin{array}{c}50 \%(28 / 56) \\
20 \%(11 / 56) \\
7 \%(4 / 56) \\
23 \%(13 / 56) \\
\end{array}$ & $\begin{array}{c}17 \%(10 / 60) \\
60 \%(36 / 60) \\
17 \%(10 / 60) \\
7 \%(4 / 60) \\
\end{array}$ & $\begin{array}{c}0.0001 \\
<0.0001 \\
0.12 \\
0.012 \\
\end{array}$ \\
\hline \multicolumn{5}{|l|}{ Patient characteristics at start of anti-VEGFR-TKI } \\
\hline Karnofsky performance status $<80$ & $12 \%(15 / 125)$ & $21 \%(13 / 62)$ & $3 \%(2 / 63)$ & 0.002 \\
\hline Neutrophils $>4.500 \mathrm{~mm}^{-3}$ & $43 \%(54 / 127)$ & $44 \%(28 / 63)$ & $41 \%(26 / 64)$ & NS \\
\hline Platelets $>400.000 \mathrm{~mm}^{-3}$ & $13 \%(17 / 127)$ & $13 \%(8 / 63)$ & $14 \%(9 / 64)$ & NS \\
\hline Haemoglobin $<11.5 \mathrm{~g} \mathrm{dl}^{-1}$ (women) or $<13 \mathrm{~g} \mathrm{dl}^{-1}$ (men) & $41 \%(52 / 126)$ & $47 \%(29 / 62)$ & $36 \%(23 / 64)$ & NS \\
\hline $\mathrm{LDH}>1.5 \times \mathrm{ULN}$ & $8 \%(9 / 120)$ & $8 \%(5 / 59)$ & $7 \%(4 / 61)$ & NS \\
\hline Corrected calcium $>10 \mathrm{mg} \mathrm{dl}^{-1}$ & $5 \%(6 / 119)$ & $7 \%(4 / 59)$ & $2 \%(1 / 60)$ & 0.16 \\
\hline Time nephrectomy to systemic treatment $<12$ months & $66 \%(82 / 125)$ & $72 \%(44 / 61)$ & $59 \%(38 / 64)$ & 0.13 \\
\hline Immunotherapy prior toanti-VEGFR-TKI & $26 \%(33 / 127)$ & $23 \%(14 / 62)$ & $29 \%(19 / 65)$ & NS \\
\hline $\begin{array}{l}\text { Site of metastasis } \\
\text { Lung } \\
\text { Liver } \\
\text { Brain } \\
\text { Bone } \\
\text { Mean number }\end{array}$ & $\begin{array}{l}80 \%(103 / 129) \\
16 \%(20 / 129) \\
7 \%(9 / 129) \\
29 \%(37 / 129) \\
2.17\end{array}$ & $\begin{array}{l}84 \%(54 / 64) \\
17 \%(11 / 64) \\
11 \%(7 / 64) \\
28 \%(18 / 64) \\
\quad 2.27\end{array}$ & $\begin{array}{l}75 \%(49 / 65) \\
14 \%(9 / 65) \\
3 \%(2 / 65) \\
29 \%(19 / 65) \\
2.08\end{array}$ & $\begin{array}{l}\text { NS } \\
\text { NS } \\
0.08 \\
\text { NS } \\
\text { NS }\end{array}$ \\
\hline $\begin{array}{l}\text { IMDC prognosis } \\
\text { Favourable } \\
\text { Intermediate } \\
\text { Poor }\end{array}$ & $\begin{array}{l}13 \%(16 / 122) \\
60 \%(73 / 122) \\
27 \%(33 / 122)\end{array}$ & $\begin{array}{l}10 \%(6 / 60) \\
57 \%(34 / 60) \\
33 \%(20 / 60)\end{array}$ & $\begin{array}{l}16 \%(10 / 62) \\
63 \%(39 / 62) \\
21 \%(13 / 62)\end{array}$ & $\begin{array}{l}0.31 \\
\text { NS } \\
0.12\end{array}$ \\
\hline \multicolumn{5}{|l|}{ First-line TKI } \\
\hline $\begin{array}{l}\text { Sunitinib } \\
\text { Sorafenib } \\
\text { Pazopanib }\end{array}$ & $\begin{array}{l}78 \%(101 / 129) \\
11 \%(14 / 129) \\
11 \%(14 / 129)\end{array}$ & $\begin{array}{l}78 \%(50 / 64) \\
14 \%(9 / 64) \\
8 \%(5 / 64)\end{array}$ & $\begin{array}{l}78 \%(51 / 65) \\
8 \%(5 / 65) \\
14 \%(9 / 65)\end{array}$ & $\begin{array}{l}\text { NS } \\
\text { NS } \\
\text { NS }\end{array}$ \\
\hline \multicolumn{5}{|l|}{ During the whole course of the disease } \\
\hline Bone metastasis & $67 \%$ (87/129) & $86 \%(55 / 64)$ & $49 \%(32 / 65)$ & $<0.0001$ \\
\hline
\end{tabular}

of the patients with tumours with a low RANK/OPG ratio $(P<0.0001)$. Higher Fuhrman grade (grade 4 vs grade $1+2+3$; $P=0.18$ ) and age at diagnosis ( $<$ median; $P=0.08$ ) were associated with shorter time to BM with a $P<0.20$, whereas T-stage at initial diagnosis $(P=0.27)$, sarcomatoid dedifferentiation ( $\leqslant 25 \%$ vs $>25 \%$; $P=0.27)$, 8Q24 amplification $(P=0.49)$, the molecular ccrcc1-4 classification $(P=0.46)$ and sex $(P=0.23)$ were not. In multivariate analysis, including age at diagnosis, Fuhrman grade and the RANK/OPG ratio, the RANK/OPG ratio remained associated with shorter time to BM (HR 0.54 (95\% CI $0.31-0.97), P=0.037)$. Again, the results for the RANK/OPG ratio did not reach the level of significance calculated after Bonferroni correction for multiple testing $(P<0.0012)$. Nevertheless, these results are an external validation of the results of Mikami et al (2009).
Gene expression and mOS since initial diagnosis. All the patients $(n=129)$ were evaluable for this analysis. Median overall survival since initial diagnosis was 49 months. Lower OPG expression $(P=0.001)$, lower DKK1 expression $(P=0.003)$, higher RANK/OPG ratio $(P<0.0001)$ and higher RANKL/OPG ratio $(P=0.008)$ were associated with shorter OS since diagnosis (Figure 1C; Table 2). A higher T-stage at initial diagnosis (T3 or $\mathrm{T} 4$ vs $\mathrm{T} 1$ or $\mathrm{T} 2 ; \quad P=0.06), 8 \mathrm{Q} 24$ amplification $(P=0.11)$, sarcomatoid dedifferentiation ( $>25 \% ; P=0.0006)$, the molecular ccrcc1-4 classification (ccrcc1 and ccrcc4 vs ccrcc2 and ccrcc3; $P=0.008)$, age at diagnosis ( $>$ median $)(P=0.19)$ and higher Fuhrman grade (grade 4 vs grade $1+2+3 ; P=0.019$ ) were associated with shorter OS since initial diagnosis with a $P<0.2$ whereas sex $(P=0.77)$ was not. As data on $8 \mathrm{Q} 24$ amplification were missing in numerous patients, this factor was not included in 
Table 2. Impact of genes associated with the development of bone metastases on outcome

\begin{tabular}{|c|c|c|c|c|c|c|c|c|c|c|c|c|}
\hline & \multicolumn{2}{|c|}{$\begin{array}{l}\text { Time to } \\
\text { metastasis }\end{array}$} & \multicolumn{2}{|c|}{$\begin{array}{l}\text { Time to bone } \\
\text { metastasis }\end{array}$} & \multicolumn{2}{|c|}{$\begin{array}{l}\text { RR on first-line } \\
\text { anti-VEGFR-TKI }\end{array}$} & \multicolumn{2}{|c|}{\begin{tabular}{|c|} 
PFS under \\
first-line \\
anti-VEGFR-TKI
\end{tabular}} & \multicolumn{2}{|c|}{$\begin{array}{l}\text { OS since start } \\
\text { of first-line } \\
\text { anti-VEGFR-TKI }\end{array}$} & \multicolumn{2}{|c|}{$\begin{array}{l}\text { OS since initial } \\
\text { diagnosis }\end{array}$} \\
\hline & Mos & $P$-value & Mos & $P$-value & $\%$ PD & $P$-value & Mos & $P$-value & Mos & $P$-value & Mos & $P$-value \\
\hline Global & 16 & NA & 77 & NA & $13 \%(16 / 127)$ & NA & 12 & NA & 26 & NA & 49 & NA \\
\hline RANK > median & 14.5 & 0.93 & 57 & 0.99 & $14 \%(9 / 65)$ & 0.66 & 11 & 0.006 & 23 & 0.001 & 43 & 0.08 \\
\hline RANK < median & 18.5 & & 82 & & $11 \%(7 / 62)$ & & 16 & $0.006(\mathrm{MV})$ & 50 & 0.001 (MV) & 67 & \\
\hline RANKL > median & 16 & 0.68 & 82 & 0.48 & $16 \%(10 / 63)$ & 0.27 & 14 & 0.76 & 28 & 0.81 & 44 & 0.35 \\
\hline RANKL < median & 14 & & 57 & & $10 \%(6 / 64)$ & & 12 & & 25 & & 53 & \\
\hline OPG > median & 24.5 & 0.18 & 110 & 0.21 & $5 \%(3 / 64)$ & 0.007 & 18 & 0.01 & 39 & 0.0008 & 68 & 0.001 \\
\hline OPG $<$ median & 11.5 & & 52 & & $21 \%(13 / 63)$ & & 9.5 & $0.023(\mathrm{MV})$ & 21 & 0.005 (MV) & 37 & 0.006 (MV) \\
\hline DKK1 > median & 28 & 0.01 & 110 & 0.33 & $11 \%(7 / 64)$ & 0.57 & 16 & 0.02 & 31 & 0.05 & 76 & 0.003 \\
\hline DKK1 < median & 10 & $0.22(\mathrm{MV})$ & 52 & & $14 \%(9 / 63)$ & & 10 & 0.015 (MV) & 23 & & 39 & 0.1 (MV) \\
\hline $\mathrm{SRC}>$ median & 24.5 & 0.05 & 77 & 0.69 & $14 \%(9 / 65)$ & 0.66 & 12 & 0.82 & 27 & 0.84 & 45 & 0.78 \\
\hline $\mathrm{SRC}<$ median & 10.5 & & 70 & & $11 \%(7 / 62)$ & & 12 & & 26 & & 53 & \\
\hline RANK/OPG > median & 8 & 0.03 & 39 & 0.04 & $21 \%(13 / 63)$ & 0.007 & 9 & 0.0002 & 19 & $<0.0001$ & 37 & $<0.0001$ \\
\hline RANK/OPG < median & 28 & $0.014(\mathrm{MV})$ & 155 & 0.037 (MV) & $5 \%(3 / 64)$ & & 19 & $0.001(\mathrm{MV})$ & 45 & $<0.0001(\mathrm{MV})$ & 76 & 0.0001 (MV) \\
\hline RANKL/OPG > median & 12 & 0.79 & 52 & 0.58 & $20 \%(13 / 64)$ & 0.008 & 10 & 0.047 & 21 & 0.003 & 37 & 0.008 \\
\hline RANKL/OPG < median & 20 & & 155 & & $5 \%(3 / 63)$ & & 16 & 0.35 (MV) & 35 & 0.033 (MV) & 67 & $0.042(\mathrm{MV})$ \\
\hline
\end{tabular}

the multivariate analysis. Four multivariate analyses were carried out including age at diagnosis, sarcomatoid dedifferentiation, Fuhrman grade and T-stage (recoded as $\mathrm{T} 1+\mathrm{T} 2$ vs $\mathrm{T} 3+\mathrm{T} 4)$ and one of the four molecular markers associated with mOS since initial diagnosis on univariate analysis. OPG (HR 1.87 (95\% CI 1.19-2.94); $P=0.006$ ), the RANK/OPG ratio (HR 2.27 (95\% CI $1.44-3.60) ; P=0.0001$ ) and the RANKL/OPG ratio (HR 1.60 (95\% CI 1.02-2.51); $P=0.042$ ) remained as independently associated with shorter OS since diagnosis. Only for the RANK/ OPG ratio, the $P$-value was below the level of significance calculated after Bonferroni correction for multiple testing $(P<0.0012)$. Nevertheless, these results are an external validation of the results of Mikami et al (2009).

Gene expression and outcome on anti-VEGFR-TKIs in the metastatic setting. In the vast majority of cases, anti-VEGFRTKIs were started at the labelled dose: $50 \mathrm{mg}$ per day 4 weeks on/2 weeks off for sunitinib and $800 \mathrm{mg}$ per day continuously for sorafenib and pazopanib. Global mPFS on first-line anti-VEGFRTKI was 12 months and mOS since start of anti-VEGFR-TKI 26 months. On univariate analysis, a high RANK expression ( $P=0.006$ and $P=0.001$, respectively) and low OPG expression ( $P=0.01$ and $P=0.0008$, respectively) were associated with shorter mPFS and mOS after start of anti-VEGFR-TKI. Lower DKK1 expression was associated with a shorter mPFS $(P=0.02)$. Elevated RANK/OPG and RANKL/OPG ratios were associated with shorter mPFS $(P=0.0002$ and $P=0.047$, respectively) and mOS $(P<0.0001$ and $P=0.003$, respectively; Figure $1 \mathrm{D}$ and $E$; Table 2). Early progressive disease was significantly more frequent in patients with tumours with low OPG expression $(P=0.007)$ and high RANK/OPG $(P=0.007)$ and RANKL/OPG ratio $(P=0.008)$. We did not find any association between expression levels of the genes and partial responses.

The factors that were taken into account for the multivariate analysis for mPFS and mOS were: baseline neutrophils, baseline platelets, baseline Karnofsky PS, baseline haemoglobin, time from diagnosis to systemic therapy, the presence of liver metastasis and $\mathrm{BM}$, sarcomatoid dedifferentiation and each of the molecular markers that was associated with mPFS or mOS on univariate analysis. The IMDC risk groups were not taken into account, because we included the factors that are part of this score. On multivariate analysis, RANK (HR 1.87 (95\% CI 1.20-2.92); $P=0.006$ ), OPG (HR 0.59 (95\% CI 0.37-0.93); $P=0.023$ ) and DKK1 (HR 1.72 (95\% CI 1.11-2.66); $P=0.015)$ were independently associated with mPFS. RANK (HR 0.46 (95\% CI 0.29-0.73); $P=0.001$ ), OPG (HR 0.51 (95\% CI 0.32-0.81); $P=0.005)$ and the RANKL/OPG ratio (HR 1.68 (95\% CI 1.04-2.70); $P=0.033$ ) were independently associated with mOS. However, the RANK/OPG ratio was the strongest independent factor associated with $\mathrm{mPFS}$ (HR 0.44 (95\% CI 0.28-0.71); $P=0.001$ ) and mOS (HR 0.31 (95\% CI 0.19-0.52); $P<0.0001$; Table 3). Both $P$-values for the RANK/OPG ratio were below the level of significance calculated after Bonferroni correction for multiple testing $(P<0.0012)$. This was also the case for the association between RANK and mOS.

Correlations with the RANK/OPG ratio. As it was most significantly associated to time to (bone)metastasis and outcome (PFS and OS on anti-VEGFR-TKIs and OS since initial diagnosis), we further focused on the RANK/OPG ratio. Tumours with an elevated RANK/OPG ratio were more often Fuhrman grade 4 $(P=0.015)$ and had more often an important component of sarcomatoid dedifferentiation (as defined $>25 \% ; P=0.035$ ). Patients with an elevated RANK/OPG ratio had more often a low Karnofsky performance status $(P=0.002)$ at start of antiVEGFR-TKIs. The RANK/OPG ratio was strongly correlated with the molecular ccrcc1-4 classification (Table 1).

Internal validation. As an internal validation, we performed all time-to-event analyses for low and high RANK/OPG ratio separately in the subgroup of Belgian $(n=55)$ and French $(n=74)$ patients. The results are reported in Table 4 . For mOS since initial diagnosis, mPFS on first-line anti-VEGFR-TKIs and mOS since start of anti-VEGFR-TKIs, the same clinically and statistically significant differences were found in both subgroups. For time to metastasis and time to BM, the differences in both subgroups were not statistically significant, but the same trend was observed. 
A

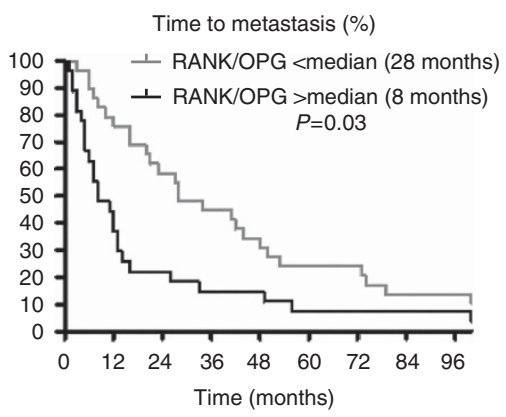

$\begin{array}{llllllll}\text { Months } & 0 & 12 & 24 & 36 & 48 & 60 & 72\end{array}$

$\begin{array}{llllllll}\text { RANK/OPG low } & 29 & 23 & 17 & 13 & 10 & 7 & 7\end{array}$

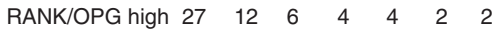

B

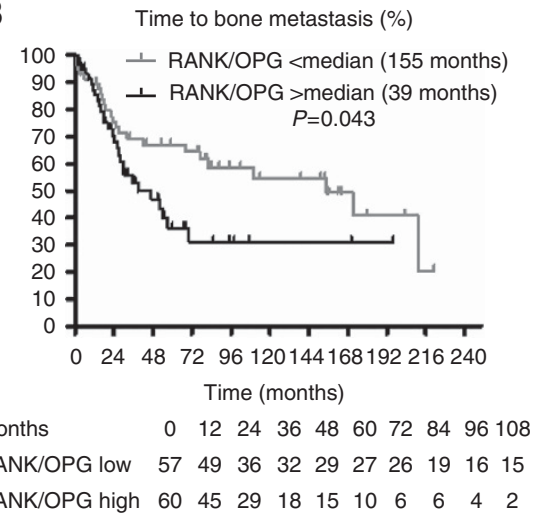

C

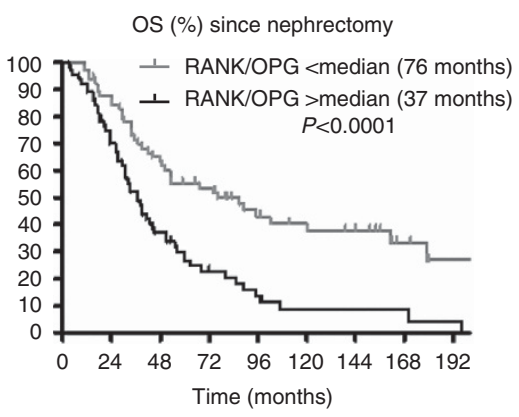

$\begin{array}{lllllllllll}\text { Months } & 0 & 12 & 24 & 36 & 48 & 60 & 72 & 84 & 96 & 108\end{array}$ RANK/OPG low $\quad \begin{array}{llllllllll}65 & 63 & 55 & 44 & 40 & 33 & 31 & 22 & 18 & 16\end{array}$ $\begin{array}{lllllllllll}\text { RANK/OPG high } & 64 & 59 & 43 & 31 & 22 & 17 & 11 & 9 & 6 & 2\end{array}$
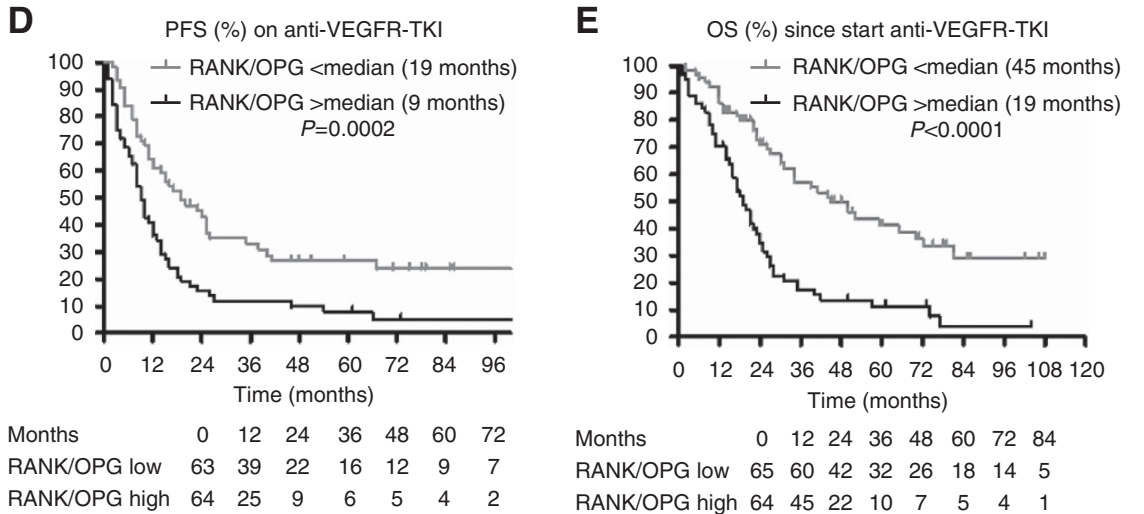

Figure 1. Kaplan-Meier analysis. (A) Association between RANK/OPG ratio and time to metastasis (in 56 patients). (B) Association between RANK/OPG- ratio and time to BM (in 117 patients). (C) Association between RANK/OPG ratio and overall survival since diagnosis (in 129 patients). (D) Association between RANK/OPG ratio and progression-free survival since start of anti-VEGFR-TKls (in 127 patients). (E) Association between RANK/OPG ratio and overall survival since start of anti-VEGFR-TKI (in 129 patients).

External validation on the TCGA cohort. The TCGA cohort (Cancer Genome Atlas Research N, 2013) includes extended molecular data but reduced clinical data. Data on the development of (bone) metastases and on response on anti-VEGFR-TKIs are not available, only OS data since nephrectomy are reported. In 232 samples with 66 events, RANK and RANKL expression were associated with OS since nephrectomy (HR 1.23, $P=0.03$ and HR $1.17, P=0.01$, respectively). DKK1, OPG and SRC expression were not associated with OS. The RANK/OPG ratio was also associated with OS (HR 1.18, $P=0.03$ ). Note that the TCGA patient series is different of our series: in our series, all patients eventually developed metastases and started with systemic therapy. Although the follow-up time is long, the number of events is also relatively low in the TCGA series.

\section{DISCUSSION}

Bone involvement in ccRCC is associated with poorer outcome on anti-VEGFR-TKIs and genes such as RANK, RANKL, OPG, SRC and $D K K 1$ are associated with the development of BM. Therefore, we aimed to investigate the relationship between tumour expression of these genes with the occurrence of BM and with survival during treatment with anti-VEGFR-TKIs.

In summary, we found that an elevated RANK/OPG ratio of expression in the primary kidney tumour is associated with shorter time to metastasis and time to BM, shorter mOS since initial diagnosis and, finally, shorter mPFS and mOS on anti-VEGFRTKIs administered in the metastatic setting. Elevated RANK expression in the primary tumour was also associated with shorter mOS on anti-VEGFR-TKIs.
At start of anti-VEGFR-TKIs, we noticed in both subgroups (RANK/OPG ratio low and high) the same number of patients with synchronous metastases at initial diagnosis, the same mean number of metastatic sites and the same number of patients with BM. Nevertheless, the moment of diagnosis of the disease and the moment on which systemic therapy has to be started are influenced by clinical complaints caused by disease progression. The tumoral evolution between the initial diagnosis and the start of systemic therapy was slower in RANK/OPG-low than in RANK/OPG-high tumours.

The major limitation of the study is the bias that can occur with random sampling in the nephrectomy specimen. ccRCC is known to be a heterogeneous tumour (Gerlinger et al, 2012). As a consequence, the expression of RANK, RANKL, OPG, SRC and DKK1 can be different depending on the site of sampling. Moreover, we studied the correlation between expression at the nephrectomy specimen but not at metastatic sites. In a considerable part of the patients, there was a long delay between the resection of their primary tumour and the occurrence of metastases, in which the expression levels of these genes can be different compared with the expression in the primary nephrectomy specimen.

An 8q21 amplification was described to be a negative prognostic factor in m-ccRCC patients treated with sunitinib (Beuselinck et al, 2015) and 8q amplification is known to be a negative prognostic factor after nephrectomy (Klatte et al, 2012). Therefore, the fact that OPG, located at locus $8 \mathrm{q} 24$, has a protective role, was somewhat surprising. Nevertheless, no association was found between 8q24 amplification and OPG expression in our patients.

In a series of 96 ccRCCs, Mikami et al (2009) has shown a higher RANKL and RANK expression in tumour tissue compared 
Table 3. Univariate analysis of previously described prognostic factors for PFS and OS on first-line anti-VEGFR-TKI

\begin{tabular}{|c|c|c|c|c|}
\hline & $\begin{array}{c}\text { Median PFS } \\
\text { (months) }\end{array}$ & $\begin{array}{c}\text { HR }(95 \% \mathrm{Cl}) \\
\text { P (UV) }\end{array}$ & $\begin{array}{l}\text { Median OS } \\
\text { (months) }\end{array}$ & $\begin{array}{c}\mathrm{HR}(95 \% \mathrm{Cl}) \\
\mathrm{P}(\mathrm{UV})\end{array}$ \\
\hline Neutrophil count $>4.500 \mathrm{~mm}^{-3}(n=54)$ & 8 & $1.81(1.18-2.79)$ & 21 & $1.57(1.02-2.42)$ \\
\hline Neutrophil count $\leqslant 4.500 \mathrm{~mm}^{-3}(n=73)$ & 17 & 0.007 & 34 & 0.04 \\
\hline Platelet count $>400.000 \mathrm{~mm}^{-3}(n=17)$ & 7 & $2.35(1.12-4.95)$ & 17 & $1.63(0.82-3.26)$ \\
\hline Platelet count $\leqslant 400.000 \mathrm{~mm}^{-3}(n=110)$ & 14 & 0.03 & 27 & 0.17 \\
\hline Karnofsky PS $\leqslant 70(n=15)$ & 4 & $9.08(3.59-22.93)$ & 9 & $16.97(6.00-47.96)$ \\
\hline Karnofsky PS > 70 $(n=110)$ & 14 & $<0.0001$ & 27 & $<0.0001$ \\
\hline $\mathrm{LDH}>1.5$ ULN $(n=9)$ & 19 & $1.21(0.52-2.82)$ & 27 & $1.17(0.54-2.56)$ \\
\hline $\mathrm{LDH} \leqslant \leq 1.5$ ULN $(n=111)$ & 12 & 0.66 & 26 & 0.69 \\
\hline $\mathrm{Hb}<11.5$ (women) or $13 \mathrm{~g} \mathrm{dl}^{-1}$ (men) $(n=52)$ & 10 & $1.62(1.05-2.48)$ & 22 & $1.52(0.98-2.35)$ \\
\hline $\mathrm{Hb}$ normal $(n=74)$ & 16 & 0.03 & 30 & 0.06 \\
\hline Corrected calcium $>10 \mathrm{mg} \mathrm{dl}^{-1}(n=6)$ & 24.5 & $0.67(0.29-1.54)$ & 36.5 & $0.76(0.31-1.85)$ \\
\hline Corrected calcium $\leqslant 10 \mathrm{mg} \mathrm{dl}^{-1}(n=113)$ & 12 & 0.34 & 25 & 0.54 \\
\hline Time from diagnosis to systemic treatment $<1$ year $(n=82)$ & 12 & $1.58(1.04-2.40)$ & 25 & $1.55(1.01-2.39)$ \\
\hline Time from diagnosis to systemic treatment $>1$ year $(n=43)$ & 13 & 0.03 & 26 & 0.04 \\
\hline Liver metastases at start of sunitinib $(n=20)$ & 8 & $2.18(1.14-4.17)$ & 15.5 & $3.04(1.49-6.20)$ \\
\hline No liver metastases at start of sunitinib $(n=109)$ & 14 & 0.02 & 28 & 0.002 \\
\hline Bone metastases at start of sunitinib $(n=37)$ & 9 & $1.53(0.96-2.43)$ & 22 & $1.74(1.06-2.84)$ \\
\hline No bone metastases at start of sunitinib $(n=92)$ & 13 & 0.07 & 30 & 0.03 \\
\hline Sarcomatoid dedifferentiation $\geqslant 25 \%(n=10)$ & 6 & $4.51(1.57-13.01)$ & 14 & $9.10(2.98-28.01)$ \\
\hline Sarcomatoid dedifferentiation $<25 \%(n=115)$ & 14 & 0.005 & 28 & 0.0001 \\
\hline No previous immunotherapy $(n=94)$ & 11 & $1.06(0.67-1.67)$ & 24 & $1.21(0.77-1.90)$ \\
\hline Previous immunotherapy $(n=33)$ & 15 & 0.81 & 34 & 0.41 \\
\hline IMDC poor risk $(n=16)$ & 7 & 0.0003 & 17 & 0.0003 \\
\hline IMDC intermediate risk $(n=73)$ & 14 & & 27 & \\
\hline IMDC good risk $(n=33)$ & 25 & & Not reached & \\
\hline $\operatorname{Corcc1}(n=38)$ & 12 & 0.0001 & 22 & $<0.0001$ \\
\hline Ccrcc2 $(n=47)$ & 19 & & 50 & \\
\hline $\operatorname{Corcc3}(n=14)$ & 19.5 & & 50 & \\
\hline Corcc4 $(n=17)$ & 5 & & 11 & \\
\hline
\end{tabular}

\begin{tabular}{|c|c|c|c|c|}
\hline & Subgroup & $\begin{array}{l}\text { RANK/OPG high } \\
\text { (months) }\end{array}$ & $\begin{array}{l}\text { RANK/OPG low } \\
\text { (months) }\end{array}$ & $P$-value \\
\hline Time to metastasis & $\begin{array}{l}\text { Belgium } \\
\text { France }\end{array}$ & $\begin{array}{r}13(n=15) \\
7(n=14)\end{array}$ & $\begin{array}{l}50(n=11) \\
16(n=16)\end{array}$ & $\begin{array}{l}0.22 \\
0.29\end{array}$ \\
\hline Time to bone metastasis & $\begin{array}{l}\text { Belgium } \\
\text { France }\end{array}$ & $\begin{array}{l}30(n=24) \\
52(n=33)\end{array}$ & $\begin{array}{r}171(n=24) \\
77(n=36)\end{array}$ & $\begin{array}{l}0.01 \\
0.55\end{array}$ \\
\hline OS since initial diagnosis & $\begin{array}{l}\text { Belgium } \\
\text { France }\end{array}$ & $\begin{array}{l}39(n=28) \\
37(n=37)\end{array}$ & $\begin{array}{r}161(n=27) \\
59(n=37)\end{array}$ & $\begin{array}{l}0.0006 \\
0.02\end{array}$ \\
\hline PFS under first-line anti-VEGFR-TKI & $\begin{array}{l}\text { Belgium } \\
\text { France }\end{array}$ & $\begin{array}{r}7(n=28) \\
10(n=35)\end{array}$ & $\begin{array}{l}19(n=27) \\
19(n=37)\end{array}$ & $\begin{array}{l}0.006 \\
0.01\end{array}$ \\
\hline OS since start of first-line anti-VEGFR-TKI & $\begin{array}{l}\text { Belgium } \\
\text { France }\end{array}$ & $\begin{array}{l}14(n=28) \\
21(n=37)\end{array}$ & $\begin{array}{l}52(n=27) \\
45(n=37)\end{array}$ & $\begin{array}{l}0.0002 \\
0.001\end{array}$ \\
\hline
\end{tabular}

with normal kidney tissue. OPG expression was downregulated in tumour tissue compared with normal kidney tissue. RANKL- or RANK-low tumours were associated with a significantly longer BM-free survival, disease-free survival and disease-specific survival.
Patients with OPG high tumours did not develop BMs and showed a longer disease-free survival than those with OPG-low tumours. Elevated RANKL and RANK expression with low OPG expression in the primary RCC tumour was a significant and independent 
Table 5. Summary of our data and previously published articles on the prognostic value of tumoral expression of RANK, RANKI and OPG

\begin{tabular}{|c|c|c|c|}
\hline & Elevated RANK & Elevated RANKL & Elevated OPG \\
\hline \multicolumn{4}{|c|}{ ccRCC (osteolytic bone metastases) } \\
\hline Beuselinck (129 pts) & Poorer PFS and OS & & Improved PFS and OS \\
\hline Mikami (96 pts) & $\begin{array}{l}\text { Poorer bone-metastasis-free survival } \\
(P<0.0001) \\
\text { Poorer disease-free survival } \\
(P=0.0013)\end{array}$ & $\begin{array}{l}\text { Poorer bone-metastasis-free survival } \\
(P<0.0001) \\
\text { Poorer disease-free survival }(P<0.0001) \text {. }\end{array}$ & $\begin{array}{l}\text { Improved bone-metastasis-free survival } \\
\text { Improved disease-free survival }(P=0.0329)\end{array}$ \\
\hline \multicolumn{4}{|c|}{ Breast carcinoma (osteoblastic and osteolytic bone metastases) } \\
\hline Sänger (1.941 ER + pts) & & & $\begin{array}{l}\text { Improved prognosis: better event-free } \\
\text { survival (HR 0.64, 95\% Cl 0.53-0.77; } \\
P<0.0001 \text { ) }\end{array}$ \\
\hline Park (185 pts) & Poorer DFS $(P=0.02)$ & $\begin{array}{l}\text { Improved bone-metastasis-free survival } \\
(P=0.03)\end{array}$ & \\
\hline Zhang (102 pts) & $\begin{array}{l}\text { Poorer PFS }(P=0.023) \\
\text { Poorer DSS }(P=0.001) \\
\text { Poorer bone-metastasis-free survival } \\
(\mathrm{HR}=2.266 ; 95 \% \mathrm{Cl} 1.289-3.984)\end{array}$ & & \\
\hline \multicolumn{4}{|c|}{ Prostate carcinoma (osteoblastic bone metastases) } \\
\hline Perez-Martinez (59 pts) & & $\begin{array}{l}\text { Poorer outcome: more biochemical } \\
\text { recurrence }(H R \text { 11.6, } P<0.001)\end{array}$ & \\
\hline \multicolumn{4}{|c|}{ NSCLC (osteolytic bone metastases) } \\
\hline Peng (52 pts) & & $\begin{array}{l}\text { Poorer outcome: more metastatic spread } \\
\text { and poorly differentiated tumours }(P<0.05)\end{array}$ & $\begin{array}{l}\text { Poorer outcome: more metastatic spread } \\
(P<0.05)\end{array}$ \\
\hline
\end{tabular}

predictor of recurrence, BM and poor prognosis (Mikami et al, 2009). Our findings are in line with the findings of Mikami et al, except for RANKL. However, in our series, all patients were selected for the occurrence of metastasis and need for systemic therapy, whereas Mikami's series is a post-nephrectomy series. Our findings are also in line with the results of Hirata et al who described that $D K K 1$ acts as a tumour suppressor gene that induces apoptosis and inhibits proliferation in human RCC (Hirata et al, 2011).

In 1.941 oestrogen receptor-positive breast cancer patients, tumour OPG expression was associated with good prognosis (Sanger et al, 2014). In metastatic breast cancer patients, RANK expression was linked with poor PFS and poor disease-specific survival. Subgroup analysis demonstrated that the significant difference in prognosis completely resulted from the occurrence of BM. In multivariate analysis, including RANK expression, age $<35$ years and non-lymph node metastasis, RANK expression was an independent predictor of BM-free survival and disease-specific survival in patients with BM (Zhang et al, 2012). Finally, in breast cancer patients, RANK expression was associated with poor disease-free survival and RANKL expression with improved BM-free survival (Park et al, 2014). In prostate cancer, RANKL expression in the primary tumour was associated with biochemical recurrence (Perez-Martinez et al, 2008). On non-small cell lung carcinoma (NSCLC) cell lines, a higher RANKL/OPG ratio was associated with higher metastatic potential $(P<0.05)$. Higher RANKL and OPG expression were observed in more advanced metastatic tumours $(P<0.05)$. Higher RANKL expression was found in poorly differentiated tumours (Peng et al, 2013). A summary of these findings is reported in Table 5 .

The RANK/RANKL/OPG pathway can be targeted with denosumab, a monoclonal anti-RANKL antibody with an activity similar to OPG, probably allowing additional anti-tumoral therapeutic possibilities besides the prevention of skeletal-related events (SREs). Bone resorption inhibitors (BRIs), such as denosumab or zoledronic acid, can interrupt the vicious circle of mutual stimulation between cancer cells and osteoclasts in the bones. Besides their efficacy in reducing SREs, BRIs have a potential anti-tumoral activity. Through the inhibition of osteolysis, less cytokines embedded in the bone become available for tumour growth stimulation. BRIs could decrease cellular migration. In human mammary epithelial cells, RANK overexpression induces epithelial-to-mesenchymal transition, stemness, migration and invasiveness (Palafox et al, 2012). In ccRCC, recombinant RANKL protein stimulates migration of cell lines in vitro and this enhanced migration can be inhibited by the administration of recombinant OPG protein (Mikami et al, 2009). Denosumab acts directly on RANK-expressing cancer cells including breast, prostate and melanoma cells (Jones et al, 2006). Zoledronic acid has a potential positive impact on OS in several tumour types with osteolytic bone disease such as NSCLC (Zarogoulidis et al, 2009), bladder carcinoma (Zaghloul et al, 2010), RCC (Saad and Eastham, 2010; Beuselinck et al, 2012; Keizman et al, 2012; Broom et al, 2014) and multiple myeloma (Morgan et al, 2010). Evidence of anti-tumoral efficacy of denosumab has been shown in prostate cancer at high risk for the development of BM: denusomab can delay the development of BM by several months (Smith et al, 2013). In a randomized trial, NSCLC patients treated with chemotherapy and denosumab experienced a longer mOS compared with patients treated with chemotherapy and zoledronic acid (Scagliotti et al, 2012).

An independent validation of these findings would pave the road for clinical trials analysing the impact of denosumab in the adjuvant setting in patients with high probability of relapse after nephrectomy in order to delay the development of (bone) metastases. Similarly, in the metastatic setting, clinical trials could study the impact on the outcome of denosumab in patients in follow-up with watchful waiting or treated with anti-VEGFR-TKIs. Moreover, denosumab is usually well tolerated, although the combination of denosumab and anti-VEGFR-TKIs could probably lead to a higher incidence of osteonecrosis of the jaw, as it was shown with concomitant anti-VEGFR-TKIs and bisphosphonates (Beuselinck et al, 2012). In both settings, RANK or OPG 
expression in the primary kidney tumour are candidate predictive biomarkers for efficacy.

\section{CONCLUSION}

In ccRCC, intratumoral expression of genes linked with the development of BM has a prognostic impact. An elevated RANK/ OPG ratio is associated with shorter median time to metastasis, time to BM, mOS since diagnosis and $\mathrm{mPFS}$ and mOS on first-line anti-VEGFR-TKIs.

\section{ACKNOWLEDGEMENTS}

The project was funded by the PNES 2007 (Programme National d'Excellence Spécialisée) from the INCa (Institut du Cancer) and by the 'Cartes d'Identité des Tumeurs' (CIT) program of the Ligue Nationale Contre le Cancer (Paris-France). The tissue collection was coordinated by the Plateforme de Ressources Biologiques de l'Hôpital Européen Georges Pompidou in Paris. We are grateful to Claudia De Toma for the coordination of the tissue collection. Benoit Beuselinck received a grant from Fondation Martine Midy (Paris, France), Fonds voor Wetenschappelijk Onderzoek Vlaanderen (Belgium) and research funding from GlaxoSmithKline. Johnny Jean-Baptiste received a research grant from the ARC (Paris, France) and ARTUR (Association pour la recherche des tumeurs du rein, Paris, France).

\section{CONFLICT OF INTEREST}

SO received honoraria from Takeda, Novartis, Sanofi, Astellas Roche and Bayer. PJJ received honoraria for advisory, consultant and/or educational activities from GlaxoSmithKline, Bayer, Novartis and Amgen. BB and WP are investigators of the EudraCT: 2011-006085-40/MetaSun trial supported by Pfizer. BB received honoraria for educational activities from GlaxoSmithKline and Amgen. Z-RJ received honorarium from Pfizer, Astellas, Lilly and Bayer. AL received consulting fees from Pfizer, Sanofi, Novartis and Amgen and research funding from Novartis and Pfizer. The remaining authors declare no conflict of interest.

\section{REFERENCES}

Beuselinck B, Job S, Becht E, Karadimou A, Verkarre V, Couchy G, Giraldo N, Rioux-Leclercq N, Molinié V, Sibony M, Elaidi R, Teghom C, Patard JJ, Méjean A, Fridman WH, Sautès-Fridman C, de Reyniès A, Oudard S, Zucman-Rossi J (2015) Molecular subtypes of clear cell renal cell carcinoma are associated to sunitinib response in the metastatic setting. Clin Cancer Res 6: 1329-1339.

Beuselinck B, Lerut E, Wolter P, Dumez H, Berkers J, Van Poppel H, Joniau S, Oyen R, De Wever L, Strijbos M, Paridaens R, Schöffski P (2014) Sarcomatoid dedifferentiation in metastatic clear cell renal cell carcinoma and outcome on treatment with anti-vascular endothelial growth factor receptor tyrosine kinase inhibitors: a retrospective analysis. Clin Genitourin Cancer 5: e205-e214.

Beuselinck B, Oudard S, Rixe O, Wolter P, Blesius A, Ayllon J, Elaidi R, Schöffski P, Barrascout E, Morel A, Escudier B, Lang H, Zucman-Rossi J, Medioni J (2011) Negative impact of bone metastasis on outcome in clear-cell renal cell carcinoma treated with sunitinib. Ann Oncol 4: 794-800.

Beuselinck B, Wolter P, Karadimou A, Elaidi R, Dumez H, Rogiers A, Van Cann T, Willems L, Body JJ, Berkers J, Van Poppel H, Lerut E, Debruyne P, Paridaens R, Schöffski P (2012) Concomitant oral tyrosine kinase inhibitors and bisphosphonates in advanced renal cell carcinoma with bone metastases. Br J Cancer 10: 1665-1671.

Broom RJ, Hinder V, Sharples K, Proctor J, Duffey S, Pollard S, Fong PC, Forgeson G, Harris DL, Jameson MB, O’Donnell A, North RT, Deva S,
Hanning FJ, Grey A, Findlay MP (2014) Everolimus and zoledronic acid in patients with renal cell carcinoma with bone metastases: a randomized first-line phase ii trial. Clin Genitourin Cancer 1: 50-58.

Cancer Genome Atlas Research N (2013) Comprehensive molecular characterization of clear cell renal cell carcinoma. Nature 7456: 43-49.

Clezardin P, Teti A (2007) Bone metastasis: pathogenesis and therapeutic implications. Clin Exp Metastasis 8: 599-608.

Gerlinger M, Rowan AJ, Horswell S, Larkin J, Endesfelder D, Gronroos E, Martinez P, Matthews N, Stewart A, Tarpey P, Varela I, Phillimore B, Begum S, McDonald NQ, Butler A, Jones D, Raine K, Latimer C, Santos CR, Nohadani M, Eklund AC, Spencer-Dene B, Clark G, Pickering L, Stamp G, Gore M, Szallasi Z, Downward J, Futreal PA, Swanton C (2012) Intratumor heterogeneity and branched evolution revealed by multiregion sequencing. $N$ Engl J Med 10: 883-892.

Heng DY, Xie W, Regan MM, Warren MA, Golshayan AR, Sahi C, Eigl BJ, Ruether JD, Cheng T, North S, Venner P, Knox JJ, Chi KN, Kollmannsberger C, McDermott DF, Oh WK, Atkins MB, Bukowski RM, Rini BI, Choueiri TK (2009) Prognostic factors for overall survival in patients with metastatic renal cell carcinoma treated with vascular endothelial growth factor-targeted agents: results from a large, multicenter study. J Clin Oncol 34: 5794-5799.

Hirata H, Hinoda Y, Nakajima K, Kawamoto K, Kikuno N, Ueno K, Yamamura S, Zaman MS, Khatri G, Chen Y, Saini S, Majid S, Deng G, Ishii N, Dahiya R (2011) Wnt antagonist DKK1 acts as a tumor suppressor gene that induces apoptosis and inhibits proliferation in human renal cell carcinoma. Int J Cancer 8: 1793-1803.

Jones DH, Nakashima T, Sanchez OH, Kozieradzki I, Komarova SV, Sarosi I, Morony S, Rubin E, Sarao R, Hojilla CV, Komnenovic V, Kong YY, Schreiber M, Dixon SJ, Sims SM, Khokha R, Wada T, Penninger JM (2006) Regulation of cancer cell migration and bone metastasis by RANKL. Nature 7084: 692-696.

Jung K, Lein M, Stephan C, Von Hosslin K, Semjonow A, Sinha P, Loening SA, Schnorr D (2004) Comparison of 10 serum bone turnover markers in prostate carcinoma patients with bone metastatic spread: diagnostic and prognostic implications. Int J Cancer 5: 783-791.

Keizman D, Ish-Shalom M, Pili R, Hammers H, Eisenberger MA, Sinibaldi V, Boursi B, Maimon N, Gottfried M, Hayat H, Peer A, Kovel S, Sella A, Berger R, Carducci MA (2012) Bisphosphonates combined with sunitinib may improve the response rate, progression free survival and overall survival of patients with bone metastases from renal cell carcinoma. Eur J Cancer 7: 1031-1037.

Klatte T, Kroeger N, Rampersaud EN, Birkhauser FD, Logan JE, Sonn G, Riss J, Rao PN, Kabbinavar FF, Belldegrun AS, Pantuck AJ (2012) Gain of chromosome 8q is associated with metastases and poor survival of patients with clear cell renal cell carcinoma. Cancer 23: 5777-5782.

McKay RR, Kroeger N, Xie W, Lee JL, Knox JJ, Bjarnason GA, MacKenzie MJ, Wood L, Srinivas S, Vaishampayan UN, Rha SY, Pal SK, Donskov F, Tantravahi SK, Rini BI, Heng DY, Choueiri TK (2014) Impact of bone and liver metastases on patients with renal cell carcinoma treated with targeted therapy. Eur Urol 3: 577-584.

Mikami S, Katsube K, Oya M, Ishida M, Kosaka T, Mizuno R, Mochizuki S, Ikeda T, Mukai M, Okada Y (2009) Increased RANKL expression is related to tumour migration and metastasis of renal cell carcinomas. J Pathol 4: 530-539.

Morgan GJ, Davies FE, Gregory WM, Cocks K, Bell SE, Szubert AJ, Navarro-Coy N, Drayson MT, Owen RG, Feyler S, Ashcroft AJ, Ross F, Byrne J, Roddie H, Rudin C, Cook G, Jackson GH, Child JA. National Cancer Research Institute Haematological Oncology Clinical Study Group (2010) First-line treatment with zoledronic acid as compared with clodronic acid in multiple myeloma (MRC Myeloma IX): a randomised controlled trial. Lancet 9757: 1989-1999.

Motzer RJ, Escudier B, Bukowski R, Rini BI, Hutson TE, Barrios CH, Lin X, Fly K, Matczak E, Gore ME (2013) Prognostic factors for survival in 1059 patients treated with sunitinib for metastatic renal cell carcinoma. Br J Cancer 12: 2470-2477.

Palafox M, Ferrer I, Pellegrini P, Vila S, Hernandez-Ortega S, Urruticoechea A, Climent F, Soler MT, Muñoz P, Viñals F, Tometsko M, Branstetter D, Dougall WC, González-Suárez E (2012) RANK induces epithelial-mesenchymal transition and stemness in human mammary epithelial cells and promotes tumorigenesis and metastasis. Cancer Res 11: 2879-2888. 
Park HS, Lee A, Chae BJ, Bae JS, Song BJ, Jung SS (2014) Expression of receptor activator of nuclear factor kappa-B as a poor prognostic marker in breast cancer. J Surg Oncol 7: 807-812.

Patil S, Figlin RA, Hutson TE, Michaelson MD, Negrier S, Kim ST, Huang X, Motzer RJ (2011) Prognostic factors for progression-free and overall survival with sunitinib targeted therapy and with cytokine as first-line therapy in patients with metastatic renal cell carcinoma. Ann Oncol 2: 295-300.

Peng X, Guo W, Ren T, Lou Z, Lu X, Zhang S, Lu Q, Sun Y (2013) Differential expression of the RANKL/RANK/OPG system is associated with bone metastasis in human non-small cell lung cancer. PloS One 3: e58361.

Perez-Martinez FC, Alonso V, Sarasa JL, Manzarbeitia F, Vela-Navarrete R, Calahorra FJ, Esbrit P (2008) Receptor activator of nuclear factor-kappaB ligand (RANKL) as a novel prognostic marker in prostate carcinoma. Histol Histopathol 6: 709-715.

Saad F, Eastham JA (2010) Zoledronic acid use in patients with bone metastases from renal cell carcinoma or bladder cancer. Semin Oncol Suppl 1: S38-S44.

Sanger N, Ruckhaberle E, Bianchini G, Heinrich T, Milde-Langosch K, Muller V, Rody A, Solomayer EF, Fehm T, Holtrich U, Becker S, Karn T (2014) OPG and PgR show similar cohort specific effects as prognostic factors in ER positive breast cancer. Mol Oncol 7: 1196-1207.

Scagliotti GV, Hirsh V, Siena S, Henry DH, Woll PJ, Manegold C, Solal-Celigny P, Rodriguez G, Krzakowski M, Mehta ND, Lipton L, García-Sáenz JA, Pereira JR, Prabhash K, Ciuleanu TE, Kanarev V, Wang H, Balakumaran A, Jacobs I (2012) Overall survival improvement in patients with lung cancer and bone metastases treated with denosumab versus zoledronic acid: subgroup analysis from a randomized phase 3 study. J Thorac Oncol 12: 1823-1829.

Smith MR, Saad F, Oudard S, Shore N, Fizazi K, Sieber P, Tombal B, Damiao R, Marx G, Miller K, Van Veldhuizen P, Morote J, Ye Z, Dansey R, Goessl C (2013) Denosumab and bone metastasis-free survival in men with nonmetastatic castration-resistant prostate cancer: exploratory analyses by baseline prostate-specific antigen doubling time. $J$ Clin Oncol 30: 3800-3806.

Zaghloul MS, Boutrus R, El-Hossieny H, Kader YA, El-Attar I, Nazmy M (2010) A prospective, randomized, placebo-controlled trial of zoledronic acid in bony metastatic bladder cancer. Int J Clin Oncol 4: 382-389.

Zarogoulidis K, Boutsikou E, Zarogoulidis P, Eleftheriadou E, Kontakiotis T, Lithoxopoulou H, Tzanakakis G, Kanakis I, Karamanos NK (2009) The impact of zoledronic acid therapy in survival of lung cancer patients with bone metastasis. Int J Cancer 7: 1705-1709.

Zhang L, Teng Y, Zhang Y, Liu J, Xu L, Qu J, Hou K, Yang X, Liu Y, Qu X (2012) Receptor activator for nuclear factor kappa B expression predicts poor prognosis in breast cancer patients with bone metastasis but not in patients with visceral metastasis. J Clin Pathol 1: 36-40.

This work is published under the standard license to publish agreement. After 12 months the work will become freely available and the license terms will switch to a Creative Commons AttributionNonCommercial-Share Alike 4.0 Unported License.

Supplementary Information accompanies this paper on British Journal of Cancer website (http://www.nature.com/bjc) 